\title{
The Bacterial Wilt Reservoir Host Solanum dulcamara Shows Resistance to Ralstonia solanacearum Infection
}

\author{
Pau Sebastià't, Roger de Pedro-Jové1,2t, Benoit Daubech', Anurag Kashyap', \\ Núria S. Coll ${ }^{1}$ and Marc Valls ${ }^{1,2 *}$ \\ ${ }^{1}$ Centre for Research in Agricultural Genomics (CSIC-IRTA-UAB-UB), Bellaterra, Spain, ${ }^{2}$ Department of Genetics, University \\ of Barcelona, Barcelona, Spain
}

OPEN ACCESS

Edited by:

Adi Avni,

Tel Aviv University, Israel

Reviewed by:

Guido Sessa,

Tel Aviv University, Israel

Antonio Cellini,

University of Bologna, Italy

${ }^{*}$ Correspondence:

Marc Valls

marcvalls@ub.edu

${ }^{\dagger}$ These authors have contributed equally to this work

Specialty section: This article was submitted to Plant Pathogen Interactions, a section of the journal

Frontiers in Plant Science

Received: 09 August 2021 Accepted: 04 October 2021 Published: 10 November 2021

Citation:

Sebastià $P$, de Pedro-Jové $R$, Daubech B, Kashyap A, Coll NS and

Valls $M$ (2021) The Bacterial Wilt Reservoir Host Solanum dulcamara Shows Resistance to Ralstonia solanacearum Infection.

Front. Plant Sci. 12:755708. doi: 10.3389/fp/s.2021.755708
Ralstonia solanacearum causes bacterial wilt, a devastating plant disease, responsible for serious losses on many crop plants. $R$. solanacearum phylotype II-B1 strains have caused important outbreaks in temperate regions, where the pathogen has been identified inside asymptomatic bittersweet (Solanum dulcamara) plants near rivers and in potato fields. S. dulcamara is a perennial species described as a reservoir host where $R$. solanacearum can overwinter, but their interaction remains uncharacterised. In this study, we have systematically analysed $R$. solanacearum infection in S. dulcamara, dissecting the behaviour of this plant compared with susceptible hosts such as tomato cv. Marmande, for which the interaction is well described. Compared with susceptible tomatoes, S. dulcamara plants (i) show delayed symptomatology and bacterial progression, (ii) restrict bacterial movement inside and between xylem vessels, (iii) limit bacterial root colonisation, and (iv) show constitutively higher lignification in the stem. Taken together, these results demonstrate that $S$. dulcamara behaves as partially resistant to bacterial wilt, a property that is enhanced at lower temperatures. This study proves that tolerance (i.e., the capacity to reduce the negative effects of infection) is not required for a wild plant to act as a reservoir host. We propose that inherent resistance (impediment to colonisation) and a perennial habit enable bittersweet plants to behave as reservoirs for $R$. solanacearum.

Keywords: bacterial wilt, Ralstonia solanacearum, disease resistance, reservoir host plants, vascular reinforcements, overwintering

\section{INTRODUCTION}

Alternate or reservoir hosts are non-target organisms that can harbour high amounts of pathogens for long periods of time and serve as an inoculum source for further infections on the primary host (Haydon et al., 2002; Morris et al., 2009). However, the term "reservoir host" has been also applied to natural or economically unimportant hosts or to hosts where infections are always nonpathogenic (Haydon et al., 2002). In many important crop diseases, non-agricultural reservoirs have also been proposed to enhance the adaptive potential of pathogens and influence disease epidemiology (Mueller et al., 2012; Monteil et al., 2013; Thinakaran et al., 2015; McCann, 2020). 
For instance, Pseudomonas syringae isolated from wild species was shown to potentially develop into novel crop pathovars in a few evolutionary steps (Monteil et al., 2013; Bartoli et al., 2015), and experimental evolution experiments with Ralstonia solanacearum demonstrated high fitness gains when this pathogen was inoculated on distant hosts (Guidot et al., 2014).

Ralstonia solanacearum is the agent causing the devastating bacterial wilt disease in over 200 plant species, including economically important crops such as potato, tomato, peanut, eggplant, and banana (Hayward, 1994; Mansfield et al., 2012; Coll and Valls, 2013). R. solanacearum can survive in the soil and waterways (Van Elsas et al., 2000; Álvarez et al., 2008a), from where it infects plants through the roots and colonises the xylem tissue, blocking water flow and causing plant wilting (Hayward, 1991; Schell, 2000). The disease is endemic in tropical and subtropical areas, but $R$. solanacearum phylotype II-B1 (formerly race 3 biovar 2) strains are adapted to cooler temperatures and have caused important outbreaks in temperate regions (Elphinstone, 1996; Janse et al., 2004; Champoiseau et al., 2009).

Survival and overwintering of $R$. solanacearum in temperate regions appears to rely on infection of perennial reservoir host plants because its persistence in the soil is limited (Olsson, 1976; Shamsuddin et al., 1978; Elphinstone, 1996). Bittersweet (Solanum dulcamara) is a common holarctic perennial weed that has been proposed to play a reservoir role in the persistence and spread of $R$. solanacearum based on several observations. Firstly, common incidences of $R$. solanacearum in $S$. dulcamara have been described along waterways (Kempenaar et al., 1998), and most disease outbreaks were related to watercourses in which infected S. dulcamara plants were present (Olsson, 1976; Elphinstone, 1996; Janse et al., 1998). Secondly, winter persistence of $R$. solanacearum in waterways correlated with the presence of the pathogen in S. dulcamara plants growing near them (Olsson, 1976; Elphinstone et al., 1998; Caruso et al., 2005). Thirdly, $R$. solanacearum was shown to colonise asymptomatically the roots and vascular tissue of $S$. dulcamara plants in the wild, and infected plants were shown to release the bacterium onto surface water via aquatic roots (Olsson, 1976; Elphinstone, 1996; Janse, 1996). Besides S. dulcamara, R. solanacearum phylotype IIB sequevar 1 strain have been found growing asymptomatically in the wild with other weeds that act as sources of inoculum to infect potato fields. These include Solanum nigrum (Olsson, 1976), Solanum cinereum (Graham and Lloyd, 1978), Urtica dioica in Europe (Wenneker et al., 1999), and a number of wild species from the Ugandan highlands (Tusiime et al., 1997). In China, tropical $R$. solanacearum strains were also identified in the weed Ageratum conyzoides L., often showing wilting symptoms (She et al., 2013).

The interactions between $R$. solanacearum and its cultivated hosts have been well-characterised, but little is known about the behaviour of this pathogen inside wild hosts. $R$. solanacearum inoculation on $S$. dulcamara in laboratory conditions has been previously reported (Wenneker et al., 1999; Álvarez et al., 2008b; Jacobs et al., 2013). A first assay screening a large number of plant species found that $66 \%$ of $S$. dulcamara plants inoculated through soil drenching became infected (Álvarez et al., 2008b). However, the authors classified this plant as tolerant to bacterial wilt because colonisation was only apparent in $25 \%$ of the plants, in which the bacterium occupied a few xylem vessels or occasionally all xylem bundles (Álvarez et al., 2008b). In another report, wilting was more apparent after soil drench inoculations, and $S$. dulcamara plants showed intermediate symptomatology compared with susceptible (Bonny Best) and resistant (Hawaii 7996) tomato plants (Jacobs et al., 2013). In a third study, all plants became infected and 97\% showed symptoms when the bacterium was directly inoculated in the stem. However, symptomatology and pathogen presence was restricted to inoculated shoots, indicating slow or no spreading of the bacterium throughout the plant (Wenneker et al., 1999). In this same study, only $13-19 \%$ of the plants were infected and 9\% showed symptoms when plants were soil-drench inoculated (Wenneker et al., 1999). In summary, S. dulcamara presents highly variable symptomatology in response to $R$. solanacearum depending on the inoculation method, although it usually shows an intermediate behaviour between a susceptible and a resistant host. The mechanisms responsible for this partial restriction of colonisation by $R$. solanacearum have not yet been described.

In this study, we have undertaken a thorough characterisation of the interaction between $R$. solanacearum and its wild host S. dulcamara. We describe the localisation of the pathogen during the infection process and the symptomatology on the plant at different temperatures and compare this interaction with that established on susceptible tomato (cv. Marmande) and potato (cv. Desirée) plants.

\section{MATERIALS AND METHODS}

\section{Plant and Bacterial Materials and Growth Conditions}

Bittersweet ( $S$. dulcamara) plants were grown from seeds harvested from wild specimens in Vidrà (NE Catalonia, Spain). The susceptible tomato (Solanum lycopersicum cv. Marmande) and susceptible potato (Solanum tuberosum cv. Desirée) plants used in this study are commercially available.

For pot experiments, S. dulcamara and S. lycopersicum cv. Marmande seeds were surface-sterilised in 35\% bleach and $0.02 \%$ Triton-X 100 for $10 \mathrm{~min}$ and then rinsed with sterile distilled water five times before sowing them in soil (Substrate 2, Klasmann-Deilmann $\mathrm{GmbH}$ ) mixed with perlite and vermiculite (30:1:1) and grown under controlled conditions for 3 weeks under a long-day photoperiod ( $16 \mathrm{~h}$ light/ $8 \mathrm{~h}$ dark) and under a light intensity of $120-150 \mu \mathrm{mol} \cdot \mathrm{m}^{-2} \cdot \mathrm{s}^{-1}$ at $22^{\circ} \mathrm{C}$ and $60 \%$ humidity. For optimal germination, S. dulcamara seeds were stratified at $4^{\circ} \mathrm{C}$ for 2 weeks before transferring them to $22^{\circ} \mathrm{C}$. S. tuberosum cv. Desirée potato plants were propagated in vitro (Puigvert et al., 2017) and 2-week old apex was sown in the same soil mixture described above and grown in the same conditions.

All infection assays were performed using the $R$. solanacearum strain UY031 (phylotype IIB, sequevar 1) isolated from potato tubers in Uruguay (Siri et al., 2011), carrying either the synthetic luxCDABE operon or the GFPuv gene, both under the control of the constitutive $p s b A$ promoter (Monteiro et al., 2012). Bacteria were routinely grown at $28-30^{\circ} \mathrm{C}$ in rich $\mathrm{B}$ medium in liquid 
cultures supplemented with gentamicin $(10 \mu \mathrm{g} / \mathrm{ml})$ and the same medium, supplemented with $0.5 \%$ glucose and $50 \mathrm{mg} / \mathrm{l}$ of triphenyl tetrazolium chloride for growth on semi-solid agar plates (Monteiro et al., 2012).

\section{Plant Inoculation and Pathogenicity Assays}

For soil-soaking and stem inoculation assays, plants were grown for 3-4 weeks. Soil-soaking root inoculations were performed by pouring $40 \mathrm{ml}$ of $10^{8}$ colony-forming units $(\mathrm{CFU}) \cdot \mathrm{ml}^{-1}$ $\left(O D_{600}=0.1\right)$ of bacterial suspension on every plant pot without disturbing the roots. Infected plants were kept in a growth chamber set at $27^{\circ} \mathrm{C}$ (exceptionally $20^{\circ} \mathrm{C}$ when indicated) and scored for wilting symptoms using a scale from 0 to 4, $0=$ healthy plant with no wilt, $1=25 \%, 2=50 \%, 3=75 \%$ of the leaves wilted, and $4=$ total wilting. Disease indexes were calculated by averaging the disease score of each plant of the experiment $(n>15)$ as indicated in previous publications with $S$. dulcamara, tomato, and potato (Álvarez et al., 2008b; Siri et al., 2011; PlanasMarquès et al., 2020). Stem-inoculation assays were performed by applying a $5 \mu \mathrm{l}$ droplet of a $10^{6} \mathrm{CFU} \cdot \mathrm{ml}^{-1}\left(O D_{600}=0.001\right)$ bacterial solution twice with a sterile $0.3 \times 13 \mathrm{~mm}$ needle (30GX $1 / 2^{\prime \prime}, \mathrm{BD}$ Microlance, Becton Dickinson) to the wounds caused at the base of the petiole after removal of the first true leaf. After inoculation, plants were kept in a growth chamber set at $27^{\circ} \mathrm{C}$ unless otherwise specified and scored for wilting symptoms as described before (Monteiro et al., 2012).

To quantify the bacterial content inside the shoots, $2 \mathrm{~cm}$ sections were excised from above the taproot (soil-soaked plants) or above the inoculation point (stem-inoculated plants), weighed, and incubated for at least $30 \mathrm{~min}$ in a sterile 2-ml Eppendorf tube with $300 \mu \mathrm{l}$ of sterile distilled water to let the bacterium ooze from the tissue. Luminescence was measured from the tubes containing excised tissue with a luminometer (FB 12, Berthold Detection Systems) to determine the bacterial concentrations since luminescence was proven to strongly correlate with bacterial density (Planas-Marquès et al., 2020). To measure bacterial counts in the root, plants inoculated as described were uprooted from day 1 to day 4 post-inoculation, and the roots were rinsed with distilled water. Approximately 1-2 $\mathrm{cm}$ of root below the tap root were cut and ground. Tissue was weighed and CFUs were counted as described above. Dilution plating of samples on rich $\mathrm{B}$ medium and $\mathrm{CFU}$ counting $24 \mathrm{~h}$ later was performed in some cases to verify luminescence results.

\section{Assessment of Bacterial Colonisation}

Plant colonisation by $R$. solanacearum was assessed using the luminescent and fluorescent strains described above. Plant stems inoculated with the luminescent strain were sliced using a sterile razor blade obtaining internode sections just below and above the petiole where inoculation had been carried out. One millimetre thick transversal cuts and $1 \mathrm{~cm}$ long longitudinal cuts were placed flat on a square plate and visualised using a live imaging system (ChemiDoc Touch Imaging System, Bio-Rad) using a 5min exposure time with $3 \times 3$ sensitivity. Images were processed using Image Lab software (Bio-Rad). Soil-soak inoculated plants with the luminescent strain were photographed by placing the whole plant in a Fuji Film LAS4000 light imager system with a 15-min exposure time.

Stem-inoculated plants with the fluorescent strain were dissected as described before and photographed using binocular microscopy equipped with a UV fluorescent lamp (BP330-385 BA420 filter) and an SZX16 stereomicroscope equipped with a DP71 camera system (Olympus) using the following settings: GFP filter, $10 \mathrm{~s}$ exposure time, ISO 1/800. Soil-soaked plants with the fluorescent strain were photographed with a Leica DM6 microscope. Bright field or fluorescence images merging the UV channel for plant structures (blue) and the GFP channel for bacteria (green) were automatically assembled by the microscope software to obtain single images including the whole root section.

Quantification of the black signal (luminescence) or the green channel (fluorescence) in the pictures was quantified using the Fiji software (United States National Institutes of Health).

\section{Tissue Stainings}

After producing root wounds with a $1 \mathrm{ml}$ pipette tip, the plants were soil-soaked with a bacterial solution of $10^{7} \mathrm{CFU} \cdot \mathrm{g}^{-1}$ $\left(O D_{600}=0.01\right)$. The day the plants showed an adequate disease index, the taproots were transversally sliced. Then four to five slices per plant were placed in a $1.5-\mathrm{ml}$ tube with $70 \%$ ethanol for at least 7 days to remove the chlorophyll. For lignin staining, individual taproot slices were placed on a microscope slide and incubated with two drops of phloroglucinol $\mathrm{HCl}$ for about $1 \mathrm{~min}$, then rinsed with $70 \%$ ethanol, and a cover slide was placed on top for visualisation in the upright microscope (Leica DM6) brightfield (Pomar et al., 2004). Mock-infected plants were inoculated with water. Lignin quantification was performed by selecting the vascular area in tomato and potato plants and comparing it with the same area in S. dulcamara plants using ImageJ software. Images were converted to a greyscale (eight-bit image) and the mean grey value was calculated.

For suberin staining, individual S. dulcamara, tomato cv. Marmande and potato cv. Desirée taproot slices were placed in a well containing a Sudan IV solution for $5 \mathrm{~min}$ and then rinsed in another well with $70 \%$ ethanol as described (Kashyap et al., 2021). Clean slices were placed on a slide and visualised with the UV filter on a Leica DM6 microscope.

\section{Statistical Analyses}

Statistical analyses were performed using Statgraphics software. All statistical tests are indicated in the respective figure legends.

\section{RESULTS}

\section{Solanum dulcamara Shows an Enhanced Capacity to Withstand $R$. solanacearum Infection in Comparison With Tomato cv. Marmande}

To analyse the symptomatology caused by $R$. solanacearum in $S$. dulcamara and compare its behaviour with that of tomato, we inoculated plants in controlled conditions using two different 
methods. First, we used a more naturalistic root inoculation method by soaking the soil with a bacterial solution without causing any wounding to plants, after which the plants were kept at $27^{\circ} \mathrm{C}$, and then the wilting symptoms were recorded over time. All susceptible tomato Marmande plants were completely wilted 14 days post-inoculation (dpi), while the symptoms just started to appear in S. dulcamara (Figure 1A). By $28 \mathrm{dpi}$, less than half of the $S$. dulcamara plants had completely wilted, showing a clear delay in the development of the disease with respect to tomato plants ( $p$-value $<0.0001$; Figure 1A).

The second method used was direct bacterial inoculation inside the plant stem vasculature, a more aggressive procedure that skips the first infection steps (root entry and vascular colonisation). As expected, disease progression was faster after stem inoculation and all the tomato plants were completely wilted at 8 dpi. S. dulcamara plants still showed a clear delay in disease progression after stem inoculation ( $p$-value $<0.0001)$ : first symptoms were apparent only by day 8 , although most plants were completely wilted by $14 \mathrm{dpi}$ (Figure 1B). Interestingly, an important proportion of $S$. dulcamara plants remained asymptomatic at the end of our experiments, especially when soil inoculation was performed. Quantification of bacterial loads in the stem over time showed an overall correlation with disease symptoms (Figures 1C,D). In soil-drench

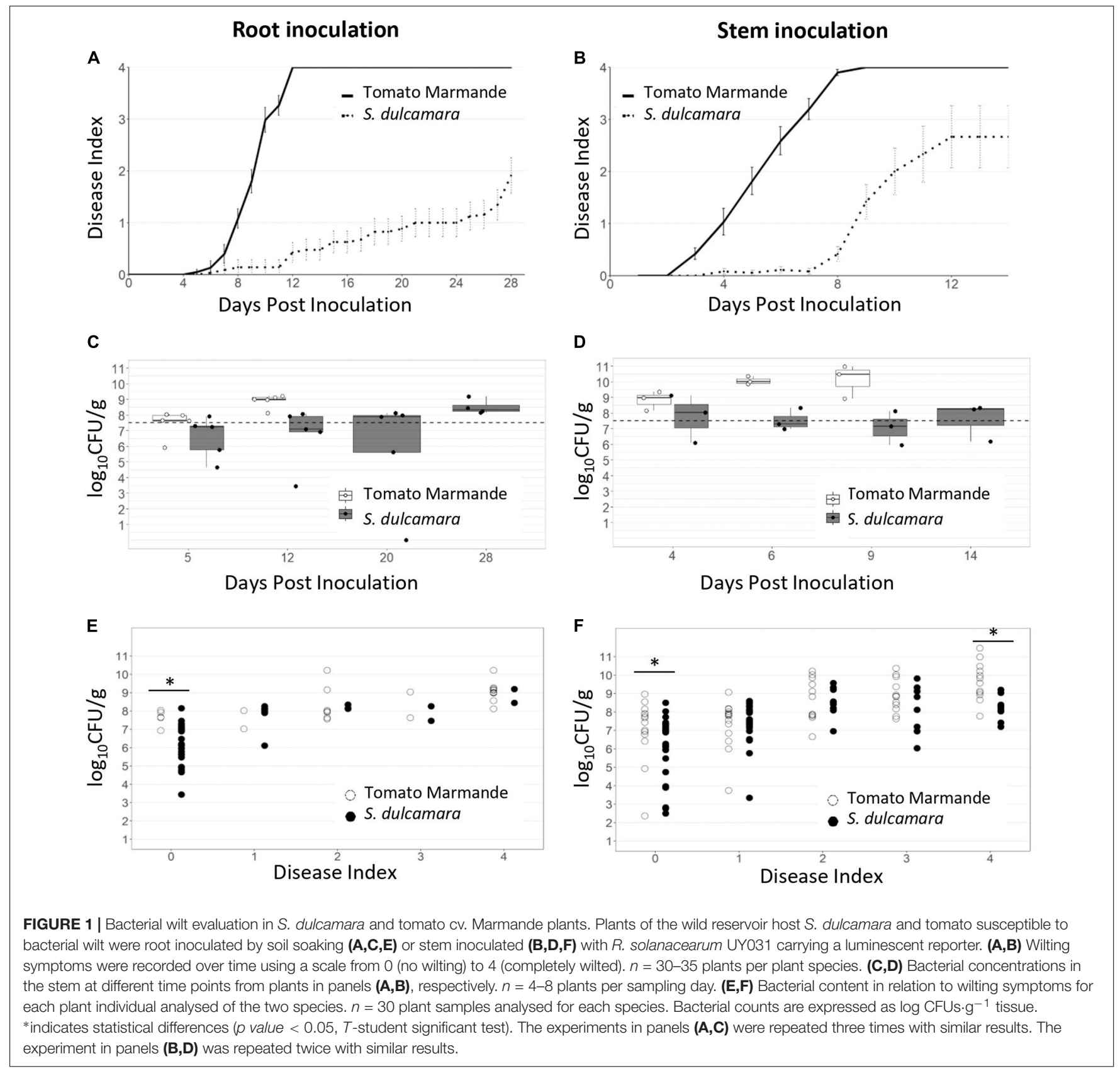


inoculations, when tomato plants were almost completely wilted (12 dpi), the bacterial concentrations in their stems were $\sim 10^{9}$ CFU.g ${ }^{-1}$, significantly higher than the $\sim 10^{7} \mathrm{CFU} \cdot \mathrm{g}^{-1}$ found in $S$. dulcamara, which only showed minor symptoms at this time point (Figure 1C). Similar results with bacterial concentrations were obtained in stem inoculation experiments although these plants displayed higher bacterial contents, especially at late disease stages, since structural barriers present in roots are circumvented in this inoculation method (Figure 1D).

To precisely determine the bacterial concentrations that the two plant species could withstand inside their tissues, we took the data from all biological replicas and plotted bacterial content in relation to wilting symptoms for each plant analysed. This representation clearly showed that, irrespective of the inoculation method, S. dulcamara and susceptible tomato bore similar bacterial concentrations at intermediate wilting stages (Figures 1E,F). However, two clear differences were observed: (i) as hinted before, at early disease stages (disease index $=1$ ) S. dulcamara plants showed lower bacterial colonisation, and (ii) bacterial loads rarely exceeded $10^{9} \mathrm{CFU} \cdot \mathrm{g}^{-1}$ in $\mathrm{S}$. dulcamara, whereas they often overcame these levels in tomato plants, leading to statistical differences when plants were completely wilted. The differences in the late disease stages were more apparent in stem inoculation experiments because this more aggressive inoculation method resulted in a higher proportion of plants showing symptoms and becoming totally wilted (disease index 4) compared with natural root inoculations by soil drenching (Figures 1E,F). In summary, S. dulcamara plants displayed delayed bacterial wilt symptom development compared with susceptible tomato plants, with most of the individuals surviving infection in the timeframe of our experiments. In addition, lower $R$. solanacearum concentrations were observed in the stems of $S$. dulcamara at early and late disease stages, suggesting delayed colonisation and restriction to bacterial growth.

\section{A High Proportion of S. dulcamara Plants Show Long-Lasting Latent Infections}

Ralstonia solanacearum infection heterogeneity amongst different plant individuals is common. To analyse the progression of bacterial colonisation and disease symptoms in single plants over time, we took advantage of the luminescent $R$. solanacearum strain used in this work, which could be visualised nondestructively inside plant tissues (Cruz et al., 2014). Stem inoculations were used in these experiments to reduce the high stochasticity of root inoculations and to facilitate infection so that a significant proportion of plants become completely wilted. Live imaging and symptom recording of whole plants were carried out along a 30-day period, after which the plants were uprooted to visualise bacterial content in the roots. As observed before, in this experiment, half of the $S$. dulcamara plants showed symptoms, and half of them remained asymptomatic at the end of the assay (Figure 2A and Supplementary Figure 1). Bacterial colonisation paralleled the onset of disease symptoms in wilting plants (Figure 2A top panel) and was always undetectable in the aerial tissues of asymptomatic plants (Figure $\mathbf{2 A}$ bottom

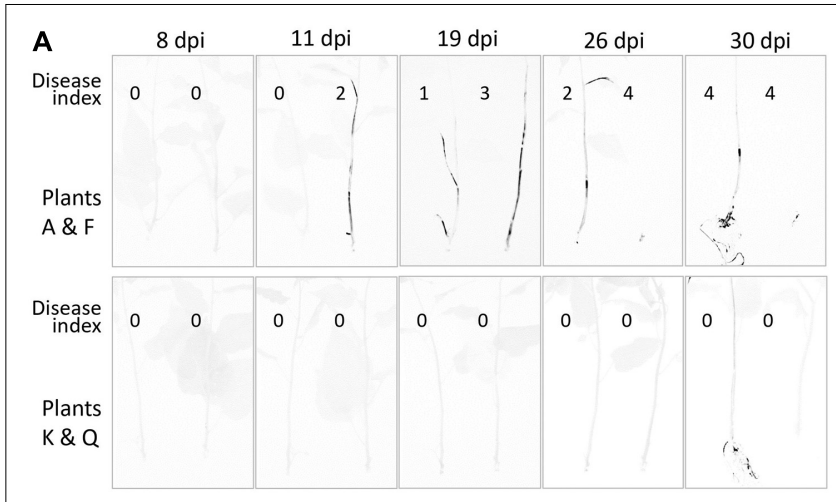

B

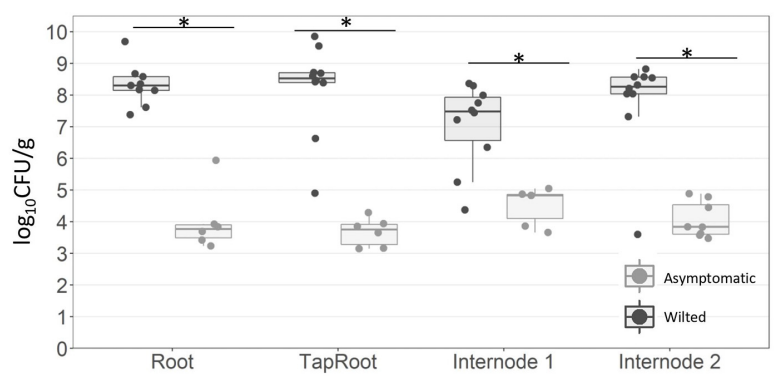

FIGURE 2 | Bacterial colonisation and multiplication in stem-inoculated S. dulcamara and tomato cv. Marmande plants. (A) Non-destructive live luminescence imaging of four representatives $S$. dulcamara plants throughout a 30-day period after root inoculation with a luminescent $R$. solanacearum strain. Two symptomatic (A \& F) and two asymptomatic ( $K \& Q$ ) plants are shown. Luminescent bacteria are detected in darker areas. Wilting symptoms (Disease index $=0-4$ ) are indicated next to each plant inside the images. (B) R. solanacearum concentrations measured at the root, taproot, internode $1(2-3 \mathrm{~cm}$ above the inoculation point) and $2(6-9 \mathrm{~cm}$ above the inoculation point) in $S$. dulcamara plants uprooted 30 days post-inoculation (dpi) with the luminescent reporter strain. The results from asymptomatic (disease index 0 ) and symptomatic (disease index 1-4) plants are shown separately. Bacterial counts were calculated from tissue luminescence and are expressed as log CFUs $\cdot g^{-1}$ tissue. ${ }^{*}$ indicates statistical differences $(p$-value $<0.05, T$-student significant test).

panel). Interestingly, $R$. solanacearum latent infections were detected in the most asymptomatic plants (four out of six plants Supplementary Figure 1), which displayed detectable luminescence in the root at $30 \mathrm{dpi}$ (Figure 2A bottom panel and Supplementary Figure 1). Quantification of the black signal from the pictures in S1 showed that the area colonised by bacteria positively correlates with the disease symptoms, except in totally wilted plants where tissue collapse and drying causes bacterial death (Supplementary Figure 2). For a more sensitive and quantitative analysis, the bacterial contents of root and stem sections of plants uprooted at $30 \mathrm{dpi}$ were calculated. The results proved that $R$. solanacearum was present in all tissues analysed from asymptomatic $S$. dulcamara plants, although bacterial concentrations were in almost all cases four orders of magnitude lower than that in symptomatic plants (Figure 2B).

In summary, long-term challenging of $S$. dulcamara with $R$. solanacearum always resulted in two distinct behaviours: plants with apparent bacterial colonisation and disease symptoms 
and plants that remained symptomless even after direct stem inoculation, but which always carried latent bacterial infections.

\section{Ralstonia solanacearum Movement Is Restricted in S. dulcamara Tissues Compared With Susceptible Tomato cv. Marmande}

We have previously demonstrated that resistant tomato varieties can restrict $R$. solanacearum root colonisation and hamper bacterial vertical and horizontal movements in the stem (PlanasMarquès et al., 2020). Thus, we hypothesised that this mechanism could be also active in $S$. dulcamara and cause the observed delay in symptom appearance and infection latency. Next, we evaluated if $S$. dulcamara plants restricted bacterial movement in the stems compared with susceptible tomatoes. To better compare bacterial behaviour in the two hosts, we stem-inoculated a large number of plants with the luminescent reporter strain and observed bacterial distribution in their stems by grouping the plants according to disease stage. The whole 4-to-5-week-old plants could not be imaged because of size limitations and reduced sensitivity due to stem thickness. Thus, we obtained stem sections of internodes one to four from plants and imaged the top and bottom slices of each section and the remaining stem longitudinally divided in two. Representative pictures presented in Figure $\mathbf{3 A}$ show that luminescence matched the location of xylem bundles and was less intense in S. dulcamara plants compared with tomatoes at early disease stages. Quantification of the luminescence signal (Supplementary Figure 3A) corroborated this result, supporting the lower bacterial loads previously observed in asymptomatic S. dulcamara (Figures 1E,F). In addition, the luminescence of xylem bundles tended to decrease with height in S. dulcamara, while it remained constant in the susceptible tomato plants (Figure 3A), suggesting stronger restriction to vertical bacterial movement along the vessels in S. dulcamara.

To further analyse if $S$. dulcamara restricts the horizontal spread of $R$. solanacearum to neighbouring xylem and parenchyma tissues, we observed shoot sections of plants steminoculated with a GFP-tagged strain (Cruz et al., 2014) using fluorescence microscopy. Representative images of internode cuts above the inoculation point showed that the bacterium was slightly more confined to the vasculature in S. dulcamara, and that a lower number of xylem vessels appeared fluorescent in this species with respect to tomato plants at comparable disease stages (Figure 3B). Despite the differences observed in asymptomatic plants, quantification of the fluorescence intensity in diseased plants (Supplementary Figure 3B) showed that colonisation was comparable in tomato and $S$. dulacamara plants displaying similar symptomatology.

Since stem inoculation skips the initial stages of infection, and to determine whether $R$. solanacearum root entry and colonisation were also restricted in $S$. dulcamara plants, we carried out a root inoculation experiment. Briefly, plants were inoculated with the luminescent reporter strain by soil drenching and the bacterial counts were measured at short times after inoculation (1-4 dpi). As can be observed in Supplementary Figure 4, bacterial concentrations were comparable at early time

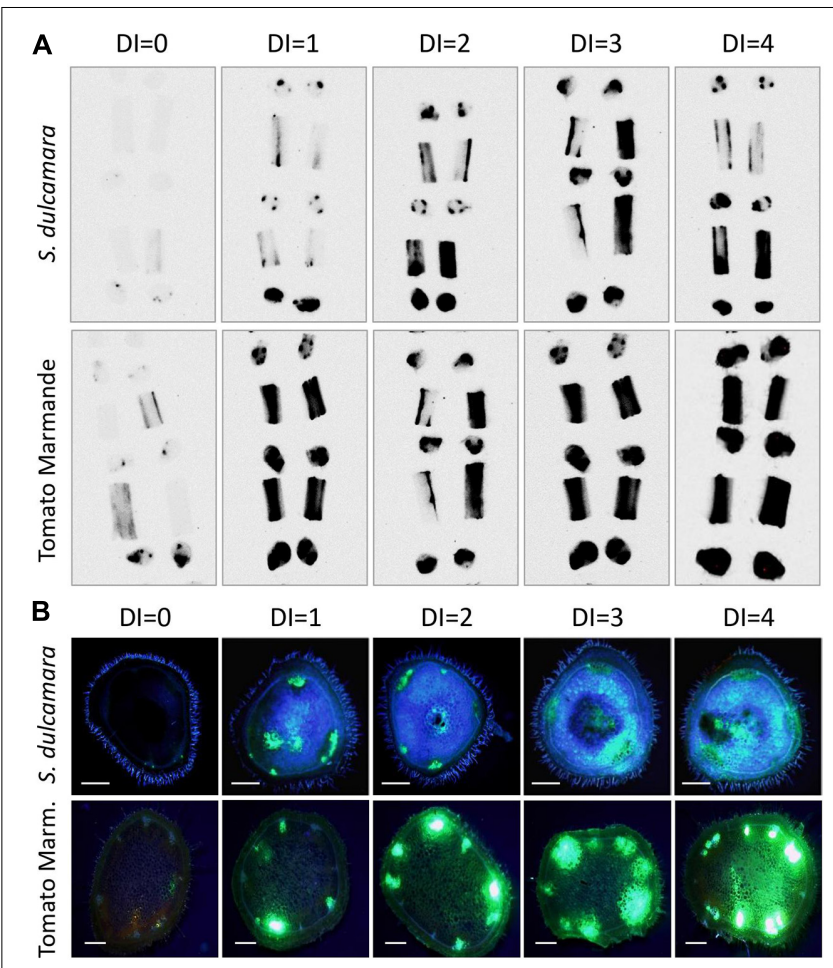

FIGURE 3|R. solanacearum distribution in stems of inoculated S. dulcamara and tomato $\mathrm{cV}$. Marmande plants. (A) Representative luminescence imaging photographs at different wilting stages (Disease index 0-4) of stem sections from S. dulcamara (top panel) and tomato (bottom panel) plants stem-inoculated with luminescent $R$. solanacearum. Luminescent bacteria are detected as dark areas in transversal and longitudinal sections of plant internodes 1-4 organised bottom to top. Inoculation points are indicated by an arrow. (B) Representative fluorescence microscopy images of stem sections from S. dulcamara (top panel) and tomato (bottom panel) plants stem-inoculated with an $R$. solanacearum strain constitutively expressing GFP. Inoculations were performed at the base of the first true leaf and transversal sections obtained in the first internode, $2 \mathrm{~cm}$ above the inoculation point. Scale bars indicate $0.5 \mathrm{~mm}$.

points, demonstrating no difference in root entry. However, statistically lower bacterial loads were observed in S. dulcamara roots at $4 \mathrm{dpi}$, proving that the root tissues of $S$. dulcamara also limit $R$. solanacearum colonisation.

Taken together, the assessment of bacterial colonisation in shoots and roots of both hosts suggests that $S$. dulcamara plants cope better with bacterial wilt because they have the ability to effectively restrict pathogen movement and colonisation inside their tissues.

\section{Solanum dulcamara Displays Dramatically Reduced Bacterial Wilt Symptoms and Bacterial Colonisation at $20^{\circ} \mathrm{C}$}

Solanum dulcamara has been demonstrated to be a reservoir plant host in which $R$. solanacearum can overwinter (Olsson, 1976; Elphinstone et al., 1998; Janse et al., 1998; Wenneker et al., 1999; Caruso et al., 2005). To test the plant behaviour at 

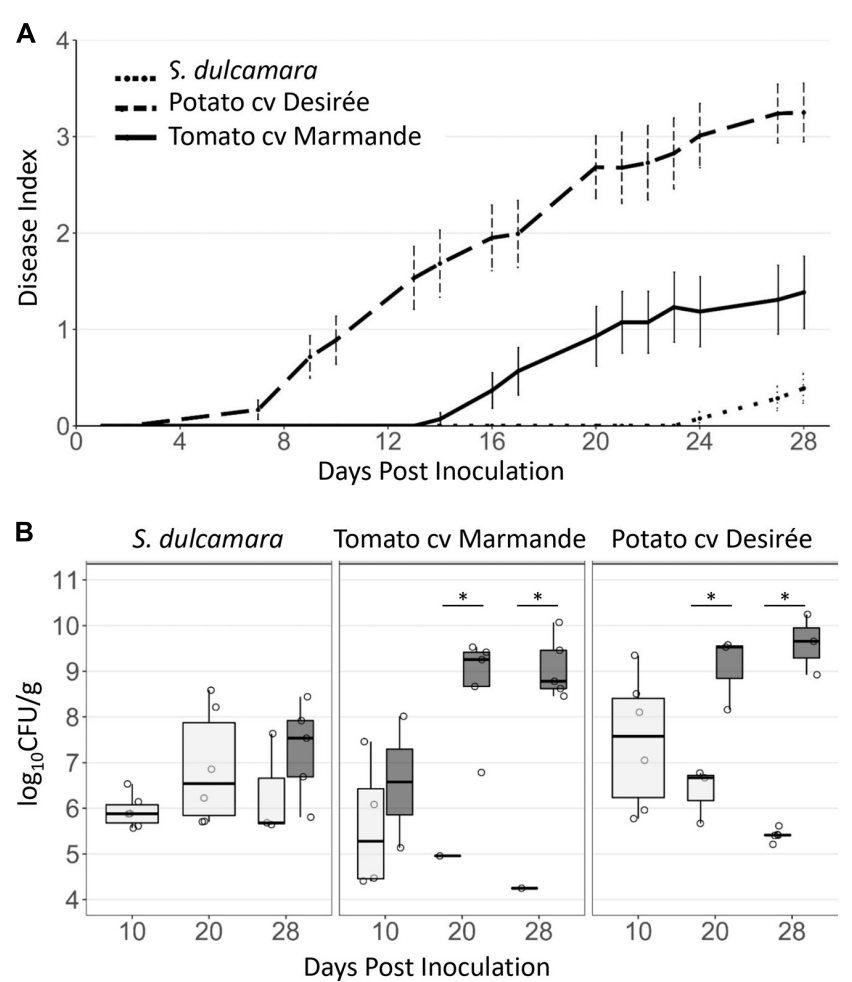

FIGURE 4 | Influence of temperature on bacterial wilt symptomatology in S. dulcamara and susceptible tomato and potato varieties. (A) Bacterial wilt symptom development $(\mathrm{O}=$ asymptomatic to 4 = completely wilted) after soil-drench inoculation in $\mathrm{S}$. dulcamara, tomato cv. Marmande and potato cv. Desirée plants inoculated with the $R$. solanacearum luminescent reporter and kept at $20^{\circ} \mathrm{C} . n=30-35$ plants per species. (B) Bacterial concentrations at the taproot level quantified by measuring the luminescence at 10, 20 and 28 dpi from S. dulcamara, susceptible tomato cv. Marmande, and susceptible potato cv. Desirée inoculated as in panel (A). Results are grouped according to disease symptoms: asymptomatic (grey, disease index 0) and symptomatic (white, disease indices $1-4)$. $n=4-8$ plants per sampling day and condition. *indicates statistical differences ( $p$ value $<0.05, T$-student significant test).

lower temperatures that mimic those encountered in temperate environments, S. dulcamara and tomato plants kept at $20^{\circ} \mathrm{C}$ were soil-soak inoculated with luminescent $R$. solanacearum, and the symptoms and bacterial loads in the stems were evaluated over time. A temperature of $20^{\circ} \mathrm{C}$ was chosen as the lower temperature, compared with $27^{\circ} \mathrm{C}$ to avoid strong effects on plant or pathogen growth. To rule out specific effects of lower temperatures on the tomato-control plants, susceptible potato plants (cv. Desirée), which are adapted to cooler conditions than tomatoes (Ingram and McCloud, 1984), were also included in this experiment. Few days after inoculation, the first tomato plants started to wilt, followed by the first potato plants 2 weeks after inoculation. By $30 \mathrm{dpi}$, around $50 \%$ of the potatoes and over $25 \%$ of the tomatoes were completely wilted (Figure 4A), in accordance with previous results in tomatoes inoculated at these temperatures with a closely related II-B1 strain (Milling et al., 2009). On the contrary, all $S$. dulcamara plants survived the infection at 30 dpi with only a few of them (six out of 25) showing mild wilting symptoms in individual leaves (disease index $<0.5$, Figure 4A). Quantification of bacterial levels in the stem over time correlated with wilting, showing overall lower bacterial titres in $S$. dulcamara than in susceptible tomato or potato plants (Figure 4B). Since most plants remained asymptomatic throughout the experimental period, bacterial concentrations were calculated separately for asymptomatic and symptomatic plants. Symptomatic plants carried bacterial counts above $10^{7}$ CFUs.g ${ }^{-1}$ in all species, concentrations being the lowest in $S$. dulcamara because disease symptoms were less developed in this species compared with the two susceptible crops. For instance, 30 days after inoculation $R$. solanacearum counts reached a maximum of $5 \times 10^{8} \mathrm{CFUs} \cdot \mathrm{g}^{-1}$ in $\mathrm{S}$. dulcamara, whereas wilted potato and tomato plants harboured up to $10^{10}$ CFUs. ${ }^{-1}$ (Figure 4B).

In conclusion, cooler temperatures slowed down disease development in all species, but this effect was more pronounced in S. dulcamara, which always survived the disease in the tested period while holding mostly asymptomatic (latent) bacterial infections.

\section{Solanum dulcamara Contains a Constitutively and Highly Lignified Xylem}

The colonisation pattern of $R$. solanacearum in $S$. dulcamara compared with tomato $\mathrm{cv}$. Marmande suggested that the former may contain vascular structures or components that make bacterial movement difficult. Lignin is one of the main components of the secondary plant cell wall, and it has been 
described to play an important role as a structural defence mechanism in resistant tomato varieties against $R$. solanacearum (Nakaho et al., 2000; Ishihara et al., 2012; Kashyap et al., 2021). Therefore, we tested whether $S$. dulcamara xylem vessels presented differential lignin accumulation in their cell walls compared with susceptible tomato and potato plants. Taproot sections obtained 9 days after mock or soil inoculation with the $R$. solanacearum GFP reporter strain were stained with phloroglucinol $\mathrm{HCl}$ to identify lignified structures. This revealed constitutive and conspicuous lignification of the S. dulcamara vasculature, whereas, in susceptible tomato and potato plants, the parenchyma cells surrounding the vascular cylinder did not appear lignified (Figure 5A). In addition, while lignification remained stable in $S$. dulcamara after $R$. solanacearum infection, both tomato and Desirée plants showed a significant decrease in lignin accumulation upon $R$. solanacearum infection (Figure $\mathbf{5 A}$ ), as previously described

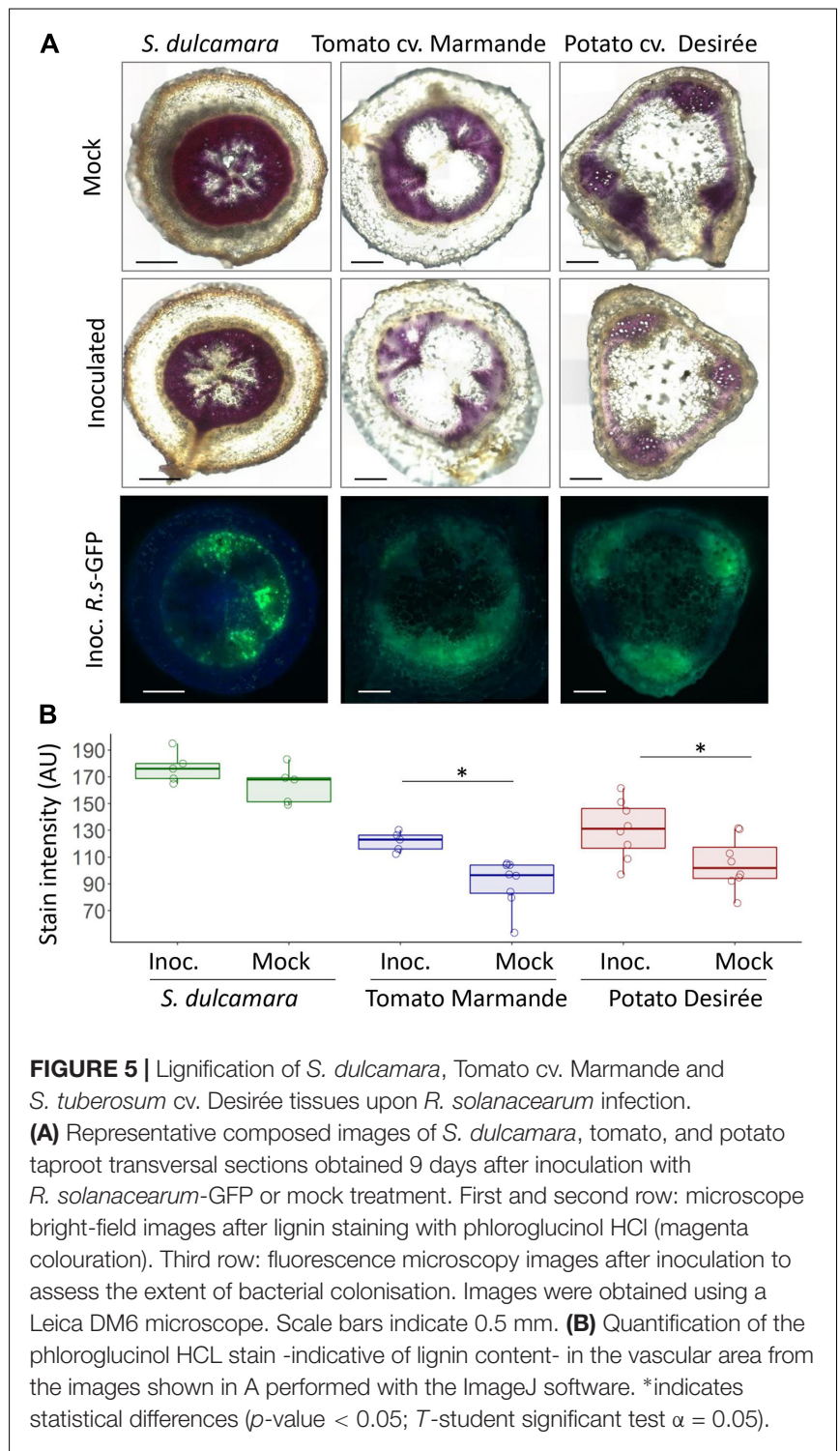

(Kashyap et al., 2021). To avoid the effect of lower bacterial concentrations usually found in S. dulcamara tissues, plants that contained comparable bacterial colonisation, as assessed by bacterial GFP fluorescence, were used for staining (Figure 5A lower panel). Quantification of the lignin stain intensity in mock and infected plants clearly confirmed a decrease in inoculated tomato and potato that was not observed in $S$. dulcamara plants (Figure 5B). The same results were observed after lignin staining from samples obtained at 6 dpi (Supplementary Figure 3), when bacterial colonisation was still low (Supplementary Figure 3A lower panel).

We have recently described (Kashyap et al., 2021) that suberin plays an important role in tomato resistance to bacterial wilt. To evaluate if this compound had an effect on the $S$. dulcamara restriction to $R$. solanacearum colonisation, we also stained inoculated or mock-treated stem sections with Sudan IV, which binds to the aliphatic domain of suberin to produce a reddish-brown colouration. No detectable increase in the accumulation of suberin was observed in S. dulcamara or in the susceptible plants after infection or mock treatment, as shown in Supplementary Figure 6.

In sum, $S$. dulcamara presented a constitutive accumulation of lignin in the xylem vessels and surrounding parenchyma that was not reduced upon pathogen infection as observed in susceptible tomato and potato, which may explain a higher restriction of bacterial colonisation in this species.

\section{DISCUSSION}

\section{Solanum dulcamara Shows Partial Resistance to Bacterial Wilt}

It has been established that plants display two main types of defence against pathogens: resistance, which is the ability of the host to limit pathogen multiplication; and tolerance, defined as the ability of the host to reduce the negative effects of infection (Clarke, 1986; Pagán and García-Arenal, 2020). However, the term tolerance has often been used incorrectly to describe partial levels of plant resistance. To differentiate bona fide tolerance from partial resistance a key aspect is that tolerance implies that the plant shows less symptoms or yield effects at equivalent levels of pathogen loads (Pagán and García-Arenal, 2020). According to these definitions, S. dulcamara shows some degree of resistance to bacterial wilt and no tolerance to the pathogen. A clear proof that tolerance does not play a role in the response of $S$. dulcamara to $R$. solanacearum is that all direct and indirect quantifications $R$. solanacearum inside $S$. dulacamara plants are comparable with those observed in tomato plants showing similar symptoms (Figures 1E,F, 2 and Supplementary Figures 2, 3, 6). The only exception to this is totally wilted plants, where bacterial populations declined, likely due to the lack of humidity in dry dead tissues (e.g., plant F, Figure 2A).

Several observations support that $S$. dulcamara plants display partial resistance to bacterial wilt (Table 1). First, irrespective of the inoculation method used, S. dulcamara showed delayed symptomatology (Figures 1A,B), delayed stem colonisation (Figures 1C,D), and slightly delayed root 
TABLE 1 | Schematic comparison of the interaction at different levels between $R$. solanacearum and a susceptible tomato, S. dulcamara, and a resistant tomato.

\begin{tabular}{lccc}
\hline & $\begin{array}{c}\text { Susceptible } \\
\text { tomato }\end{array}$ & S. dulcamara & $\begin{array}{c}\text { Resistant } \\
\text { tomato }\end{array}$ \\
\hline Disease symptoms & +++ & ++ & \pm \\
Bacterial levels in roots & +++ & ++ & + \\
Bacterial levels in stems & +++ & ++ & + \\
Bacterial vertical spread & +++ & ++ & + \\
Bacterial horizontal spread & +++ & ++ & $\mathrm{NT}$ \\
Symptoms at lower temp. & ++ & ++ & +++ \\
Structural reinforcements & \pm & & + \\
\hline
\end{tabular}

t: few or inexistent; +: low levels; ++: intermediate levels; +++: high levels; NT: not tested.

colonisation (Supplementary Figure 4). These phenotypes are similar but less pronounced than those observed in resistant tomato cv. Hawaii 7996 (Table 1 and Planas-Marquès et al., 2020). Further proofs of this are that an important proportion of S. dulcamara plants remained asymptomatic when tomatoes were completely wilted and that stem inoculation and large numbers had to be used to obtain enough plants at advanced disease stages to compare with susceptible tomatoes.

Second, S. dulcamara restricted $R$. solanacearum vertical movement in the stem. A luminescent $R$. solanacearum reporter strain was able to entirely colonise susceptible tomato, while in $S$. dulcamara plants the upper stem displayed less pathogen colonisation (Figures 2, 3A). In accordance with this, it has been described in $S$. dulcamara that symptomatology and pathogen presence was restricted only to shoots directly inoculated, indicating slow or no spreading of the bacterium throughout the plant (Wenneker et al., 1999). We previously reported similar behaviour, although clearly more apparent (Table 1) in resistant tomatoes (Planas-Marquès et al., 2020).

Third, bacterial movement between xylem vessels was also limited in $S$. dulcamara compared with susceptible tomatoes (Figure 3B). This could explain the stem colonisation delay observed, as $S$. dulcamara restricts $R$. solanacearum to specific xylem vessels, while others remain pathogenfree, a behaviour also reported for the resistant tomato (Planas-Marquès et al., 2020).

Taken together, our results confirm previous studies that reported S. dulcamara as partially resistant to bacterial wilt, although it was misleadingly described as tolerance. Discrepancies amongst previous reports where infection rates varied from 100 to $66 \%$ and 13 to $19 \%$ (Wenneker et al., 1999; Álvarez et al., 2008b; Jacobs et al., 2013) can be explained by the different inoculation methods used, by different assay conditions (e.g., temperature and inoculum), and/or by genetic differences amongst the plant accessions used.

\section{Solanum dulcamara Carries Latent $R$. solanacearum Infections at $20^{\circ} \mathrm{C}$}

Three conditions are required for the establishment and development of plant diseases: a virulent pathogen, a susceptible host, and permissive environmental conditions (McNew, 1960).
We thus explored the behaviour of $S$. dulcamara resistance to bacterial wilt when plants are grown and inoculated at lower temperatures. A decrease in temperature resulted in delayed symptom appearance and bacterial colonisation in both the susceptible hosts and in S. dulcamara (Figure 4) and the difference in resistance between them was maintained. This indicates that the ability of a pathogen to cause disease is compromised at a lower temperature, as has been described for many pathosystems. Thus, in these conditions, S. dulcamara plants displayed a stronger resistance to the disease, as all plants survived a month after inoculation and only very few of them showed minor wilting symptoms (Figure 4A and Table 1), but they all carried asymptomatic (latent) infections (Figure 4B).

Tolerance to disease, i.e., the ability to keep high bacterial levels without showing symptoms, has been proposed as a key trait for plants to act as reservoir hosts, providing a source of pathogen inoculum that spreads when environmental conditions become appropriate (Roberts and Heesterbeek, 2020). Based on our findings with $S$. dulcamara (Table 1), we propose that resistance, i.e., limiting pathogen colonisation, could also enable plants to act as reservoirs. Intermediate resistance would be required in this case for two reasons: first, it would allow a limited amount of pathogen to colonise and survive under unfavourable environmental conditions, such as winter temperatures, as latent infections inside the plant, and second, when environmental conditions favour disease (high temperature in our case), the pathogen could overcome resistance in some plants, multiplying to high numbers and spreading to other hosts. These two conditions could not take place if plants were either fully resistant or tolerant. This theory is supported by the original description of $S$. dulcamara as a symptomless $R$. solanacearum carrier in the wild (Olsson, 1976; Hayward, 1991), and studies show that environmental conditions can break resistance to the disease. For instance, in eucalypt, $R$. solanacearum usually behaves as a latent colonist, and only in the presence of other stressing factors the pathogen is able to proliferate and cause disease (Coutinho and Wingfield, 2017).

\section{Constitutive Xylem Lignification in an S. dulcamara Is Likely Responsible for Its Resistance to $R$. solanacearum}

Observation of $S$. dulcamara stem transversal sections indicated a highly lignified xylem compared with susceptible tomato and potato varieties (Figure 5 and Supplementary Figure 5). This is in accordance with previous reports that lignin biosynthesis genes were upregulated in the bacterial wilt resistant tomato variety LS-89 upon $R$. solanacearum infection (Ishihara et al., 2012). Furthermore, we have recently shown striking differences in lignin composition between susceptible (Marmande) and resistant (Hawaii 7996) tomatoes, which indicate that the properties of paravascular lignin may be key for resistance to bacterial wilt (Kashyap et al., 2021).

Interestingly, S. dulcamara lignification was already high in mock-treated plants and was not affected by infection (Figure 5 and Supplementary Figure 5), whereas susceptible tomato and 
potato plants reduced their lignin content significantly both at 6 and 9 dpi upon $R$. solanacearum inoculation. This constitutive lignification and the irrelevance of suberin components, whose levels are comparable with susceptible plants (Supplementary Figure 6), are key differences in the factors controlling S. dulcamara resistance compared with tomato H7996, where suberin components play a major role (Kashyap et al., 2021). The fact that $S$. dulcamara is a perennial, with the ensuing secondary growth present in these plants (Caldwell, 2016), may explain the high lignification of its tissues, which must be even more pronounced in wild plants- and that this phenomenon is not inducible like in the annual tomato plants.

The correlation observed between resistance to infection and the presence of cell wall reinforcements both in resistant tomato and in the wild $S$. dulcamara plants indicates that lignification hinders $R$. solanacearum movement throughout the plant tissues and entry in the xylem vessels. This would explain the delay in symptom appearance compared with susceptible tomatoes (Figures 1A,B) and also account for the low bacterial content in inoculated plants that remained healthy (Figures 1C-F). Microscopically, cell wall reinforcements could have a major contribution to the stronger bacterial restriction in specific xylem vessels and decreased spread to neighbouring parenchyma cells, as observed in S. dulcamara compared with tomato cv. Marmande (Figure 3). Restriction of $R$. solanacearum infection to primary xylem vessels while secondary xylem vessels remain functional (Esau, 1977) could explain why $S$. dulcamara better survives the infection. Restricting pathogen movement is an important mechanism for resistance against $R$. solanacearum in tomato (Caldwell et al., 2017; Planas-Marquès et al., 2020) and potato (Cruz et al., 2014) that is also conserved in grapevine against Xylella fastidiosa (Chatterjee et al., 2008).

In summary, strong preexisting lignified xylem vessels present in S. dulcamara are likely the factor that supports its resistance to $R$. solanacearum and allows it to behave like a reservoir host. The generation of $S$. dulcamara mutants in lignin biosynthesis genes would be extremely useful to confirm this hypothesis.

\section{DATA AVAILABILITY STATEMENT}

The original contributions presented in the study are included in the article/Supplementary Material, further inquiries can be directed to the corresponding author.

\section{REFERENCES}

Álvarez, B., López, M. M., and Biosca, E. G. (2008a). Survival strategies and pathogenicity of Ralstonia solanacearum phylotype II subjected to prolonged starvation in environmental water microcosms. Microbiology 154, 3590-3598. doi: 10.1099/mic.0.2008/019448-0

Álvarez, B., Vasse, J., Le-Courtois, V., Trigalet-Démery, D., López, M. M., and Trigalet, A. (2008b). Comparative behavior of Ralstonia solanacearum biovar 2 in diverse plant species. Phytopathology 98, 59-68. doi: 10.1094/PHYTO-98$1-0059$

\section{AUTHOR CONTRIBUTIONS}

MV, PS, NC, and AK conceived and designed the work. PS, AK, RP-J, and BD performed the experiments and statistical analyses. MV and NC provided reagents and materials. PS, RP-J, and MV analysed the results and edited the figures. MV, PS, and NC wrote the manuscript. All authors have made a substantial, direct and intellectual contribution to the work, and approved it for publication.

\section{FUNDING}

This work was supported by the Spanish Ministry of Economy and Competitiveness (AGL2016-78002-R) and the Ministry of Science and Innovation PID2019-108595RBI00/AEI/10.13039/501100011033. We also acknowledge financial support from the "Severo Ochoa Program for Centers of Excellence in R\&D" (SEV-2015-0533 and CEX2019-000902$S$ ), and the CERCA Program from the Catalan Government (Generalitat de Catalunya). The funders had no role in study design, data collection and analysis, decision to publish, or preparation of the manuscript. PS held an INPHINIT Programme fellowship from Fundació "La Caixa” and AK was a recipient of a Netaji Subhas - Indian Council of Agricultural Research (ICAR) International Fellowship. RP-J received FI and FPU fellowships from Generalitat de Catalunya and the Ministry of Education and Professional Formation, respectively. $\mathrm{BD}$ have received funding from the European Union's Horizon 2020 Research and Innovation Programme under the Marie Skłodowska-Curie Grant Agreement No. 945043.

\section{ACKNOWLEDGMENTS}

The authors are grateful to all the members of the Bacterial Pathogens and Plant Cell Death Team (Center for Research in Agricultural Genomics, CRAG), especially to Marc Planas for their technical assistance and critical comments.

\section{SUPPLEMENTARY MATERIAL}

The Supplementary Material for this article can be found online at: https://www.frontiersin.org/articles/10.3389/fpls.2021. 755708/full\#supplementary-material

Bartoli, C., Lamichhane, J. R., Berge, O., Guilbaud, C., Varvaro, L., Balestra, G. M., et al. (2015). A framework to gauge the epidemic potential of plant pathogens in environmental reservoirs: the example of kiwifruit canker. Mol. Plant Pathol. 16, 137-149. doi: 10.1111/mpp.12167

Caldwell, D. (2016). The Role of Root Anatomy and Root Architecture in Resistance to Ralstonia solanacearum. Ph. D. thesis. West Lafayette: Purdue University.

Caldwell, D., Kim, B. S., and Iyer-Pascuzzi, A. S. (2017). Ralstonia solanacearum differentially colonizes roots of resistant and susceptible tomato plants. Phytopathology 107, 528-536. doi: 10.1094/PHYTO-09-160353-R 
Caruso, P., Palomo, J. L., Bertolini, E., Álvarez, B., López, M. M., and Biosca, E. G. (2005). Seasonal variation of Ralstonia solanacearum biovar 2 populations in a Spanish river: recovery of stressed cells at low temperatures. Appl. Environ. Microbiol. 71, 140-148. doi: 10.1128/AEM.71.1.140-148.2005

Champoiseau, P. G., Jones, J. B., and Allen, C. (2009). Ralstonia solanacearum Race 3 biovar 2 causes tropical losses and temperate anxieties. Plant Health Progr. 10:35. doi: 10.1094/PHP-2009-0313-01-RV

Chatterjee, S., Newman, K. L., and Lindow, S. E. (2008). Cell-to-cell signaling in Xylella fastidiosa suppresses movement and xylem vessel colonization in grape. Mol. Plant-Microbe Interact. 21, 1309-1315. doi: 10.1094/MPMI-21-10-1309

Clarke, D. D. (1986). Tolerance of parasites and disease in plants and its significance in host-parasite interactions. Adv. Plant Pathol. 5, 161-198.

Coll, N. S., and Valls, M. (2013). Current knowledge on the Ralstonia solanacearum type III secretion system. Microb. Biotechnol. 6, 614-620. doi: 10.1111/17517915.12056

Coutinho, T. A., and Wingfield, M. J. (2017). Ralstonia solanacearum and r. Pseudosolanacearum on eucalyptus: opportunists or primary pathogens? Front. Plant Sci. 8:761. doi: 10.3389/fpls.2017.00761

Cruz, A. P. Z., Ferreira, V., Pianzzola, M. J., Siri, M. I., Coll, N. S., and Valls, M. (2014). A novel, sensitive method to evaluate potato germplasm for bacterial wilt resistance using a luminescent Ralstonia solanacearum reporter strain. Mol. Plant Microbe Interact. 27, 277-285. doi: 10.1094/MPMI-10-13-0303-FI

Elphinstone, J. G. (1996). Survival and possibilities for extinction of Pseudomonas solanacearum (Smith) Smith in cool climates. Potato Res. 39, 403-410. doi: 10.1007/BF02357946

Elphinstone, J. G., Stanford, H., Stead, D. E., and Hutton, S. (1998). Survival and transmission of Ralstonia solanacearum in aquatic plants of Solanum dulcamara and associated surface water in England. EPPO Bull. 94, 93-94. doi: 10.1111/j. 1365-2338.1998.tb00709.x

Esau, K. (1977). Anatomy of Seed Plants, 2nd Edn. New York: John Wiley \& Sons Ltd. doi: $10.2307 / 2418500$

Graham, J., and Lloyd, A. B. (1978). Solanum cinereum R. Br., a wild host of Pseudomonas solanacearum biotype II. J. Aust. Inst. Agric. Sci. 44, 124-126.

Guidot, A., Jiang, W., Ferdy, J. B., Thébaud, C., Barberis, P., Gouzy, J., et al. (2014). Multihost experimental evolution of the pathogen ralstonia solanacearum unveils genes involved in adaptation to plants. Mol. Biol. Evol. 31, 2913-2928. doi: 10.1093/molbev/msu229

Haydon, D. T., Cleaveland, S., Taylor, L. H., and Laurenson, M. K. (2002). Identifying reservoirs of infection: a conceptual and practical challenge. Emerg. Infect. Dis. 8, 1468-1473. doi: 10.3201/eid0812.010317

Hayward, A. C. (1991). Biology and Epidemiology of Bacterial Wilt caused by Pseudomonas solanacearum. Ann. Rev. Phytopathol. 29, 65-87. doi: 10.1146/ annurev.py.29.090191.000433

Hayward, A. C. (1994). “The hosts of Pseudomonas solanacearum," in Bacterial Wilt: the Disease and Its Causative Agent, Pseudomonas solanacearum, eds A. Hayward and G. Hartman (Wallingford: CAB International), 9-24.

Ingram, K. T., and McCloud, D. E. (1984). Simulation of Potato Crop Growth and Development 1. Crop Sci. 24, 21-27. doi: 10.2135/cropsci1984. 0011183X002400010006x

Ishihara, T., Mitsuhara, I., Takahashi, H., and Nakaho, K. (2012). Transcriptome analysis of quantitative resistance-specific response upon Ralstonia solanacearum infection in Tomato. PLoS One 7:e46763. doi: 10.1371/journal.pone.0046763

Jacobs, J. M., Milling, A., Mitra, R. M., Hogan, C. S., Ailloud, F., Prior, P., et al. (2013). Ralstonia solanacearum requires pops, an ancient avre-family effector, for virulence and to overcome salicylic acid-mediated defenses during tomato pathogenesis. mBio 4, e00875-13. doi: 10.1128/mBio.00875-13

Janse, J. D. (1996). Potato brown rot in western Europe - history, present occurrence and some remarks on possible origin, epidemiology and control strategies. EPPO Bull. 26, 679-695. doi: 10.1111/j.1365-2338.1996.tb01512.x

Janse, J. D., Araluppan, F. A. X., Schans, J., Wenneker, M., and Westerhuis, W. (1998). "Experiences with bacterial brown rot Ralstonia solanacearum biovar 2, race 3 in the Netherlands," in Bacterial Wilt Disease, eds P. Prior, C. Allen, and J. Elphinstone (Berlin: Springer), 146-152. doi: 10.1007/978-3-662-03592-4_21

Janse, J. D., Van Den Beld, H. E., Elphinstone, J., Simpkins, S., Tjou-Tam-Sin, N. N. A., and Van Vaerenbergh, J. (2004). Introduction to Europe of Ralstonia solanacearum biovar 2, race 3 in Pelargonium zonale cuttings. J. Plant Pathol. $86,147-155$.
Kashyap, A., Capellades, M., Zhang, W., Srinivasan, S., Laromaine, A., Serra, O., et al. (2021). Induced ligno-suberin vascular coating and tyramine-derived hydroxycinnamic acid amides restrict Ralstonia solanacearum colonization in resistant tomato roots. bioRxiv [Preprint]. doi: 10.1101/2021.06.15.448549

Kempenaar, C., Groeneveld, R. M. W., Lotz, L. A. P., Wenneker, M., and Janse, J. D. (1998). Ecology and control of bittersweet in relation to brown rot. Gewasbescherming 29, 119-123.

Mansfield, J., Genin, S., Magori, S., Citovsky, V., Sriariyanum, M., Ronald, P., et al. (2012). Top 10 plant pathogenic bacteria in molecular plant pathology. Mol. Plant Pathol. 13, 614-629. doi: 10.1111/j.1364-3703.2012.00804.x

McCann, H. C. (2020). Skirmish or war: the emergence of agricultural plant pathogens. Curr. Opin. Plant Biol. 50, 147-152. doi: 10.1016/j.pbi.2020.06.003

McNew, G. L. (1960). "The nature, origin, and evolution of parasitism," in Plant Pathology: An Advanced Treatise, eds J. G. Horsfall and A. E. Dimond (New York: Academic Press), 19-69.

Milling, A., Meng, F., Denny, T. P., and Allen, C. (2009). Interactions with hosts at cool temperatures, not cold tolerance, explain the unique epidemiology of Ralstonia solanacearum race 3 biovar 2. Phytopathology 99, 1127-1134. doi: 10.1094/PHYTO-99-10-1127

Monteil, C. L., Cai, R., Liu, H., Mechan Llontop, M. E., Leman, S., Studholme, D. J., et al. (2013). Nonagricultural reservoirs contribute to emergence and evolution of Pseudomonas syringae crop pathogens. New Phytol. 199, 800-811. doi: $10.1111 / \mathrm{nph} .12316$

Monteiro, F., Solé, M., Van Dijk, I., and Valls, M. (2012). A chromosomal insertion toolbox for promoter probing, mutant complementation, and pathogenicity studies in Ralstonia solanacearum. Mol. Plant Microbe Interact. 25, 557-568. doi: 10.1094/MPMI-07-11-0201

Morris, C. E., Bardin, M., Kinkel, L. L., Moury, B., Nicot, P. C., and Sands, D. C. (2009). Expanding the paradigms of plant pathogen life history and evolution of parasitic fitness beyond agricultural boundaries. PLoS Pathog. 5:e1000693. doi: 10.1371/journal.ppat.1000693

Mueller, E. E., Groves, R. L., and Gratton, C. (2012). Crop and non-crop plants as potential reservoir hosts of Alfalfa mosaic virus and cucumber mosaic virus for spread to commercial snap bean. Plant Dis. 96, 506-514. doi: 10.1094/PDIS02-11-0089

Nakaho, K., Hibino, H., and Miyagawa, H. (2000). Possible mechanisms limiting movement of Ralstonia solanacearum in resistant tomato tissues. J. Phytopathol. 148, 181-190. doi: 10.1046/j.1439-0434.2000.00476.x

Olsson, K. (1976). Experience of Brown Rot Caused by Pseudomonas solanacearum (Smith) Smith in Sweden. EPPO Bull. 6, 199-207. doi: 10.1111/j.1365-2338. 1976.tb01546.x

Pagán, I., and García-Arenal, F. (2020). Tolerance of plants to Pathogens: a unifying view. Ann. Rev. Phytopathol. 58, 1-20. doi: 10.1146/annurev-phyto-010820012749

Planas-Marquès, M., Kressin, J. P., Kashyap, A., Panthee, D. R., Louws, F. J., Coll, N. S., et al. (2020). Four bottlenecks restrict colonization and invasion by the pathogen Ralstonia solanacearum in resistant tomato. J. Exp. Bot. 71, 2157-2171. doi: 10.1093/jxb/erz562

Pomar, F., Novo, M., Bernal, M. A., Merino, F., and Barceló, A. R. (2004). Changes in stem lignins (monomer composition and crosslinking) and peroxidase are related with the maintenance of leaf photosynthetic integrity during Verticillium wilt in Capsicum annuum. New Phytol. 163, 111-123. doi: 10. 1111/j.1469-8137.2004.01092.x

Puigvert, M., Guarischi-Sousa, R., Zuluaga, P., Coll, N. S., Macho, A. P., Setubal, J. C., et al. (2017). Transcriptomes of Ralstonia solanacearum during root colonization of solanum commersonii. Front. Plant Sci. 8:370. doi: 10.3389/ fpls.2017.00370

Roberts, M. G., and Heesterbeek, J. A. P. (2020). Characterizing reservoirs of infection and the maintenance of pathogens in ecosystems. J. R. Soc. Interface 17:20190540. doi: 10.1098/rsif.2019.0540

Schell, M. A. (2000). Control of virulence and pathogenicity genes of Ralstonia solanacearum by an elaborate sensory network. Ann. Rev. Phytopathol. 38, 263-292. doi: 10.1146/annurev.phyto.38.1.263

Shamsuddin, N., Lloyd, A. B., and Graham, J. (1978). Survival of the potato strain of Pseudomonas solanacearum in soil. J. Aust. Inst. Agric. Sci. 44, 212-215.

She, X. M., He, Z. F., Luo, F. F., and Li, H. P. (2013). First report of bacterial wilt caused by Ralstonia solanacearum on Ageratum conyzoides in China. Plant Dis. 97, 418-418. doi: 10.1094/PDIS-08-12-0780-PDN 
Siri, M. I., Sanabria, A., and Pianzzola, M. J. (2011). Genetic diversity and aggressiveness of Ralstonia solanacearum strains causing bacterial wilt of potato in Uruguay. Plant Dis. 95, 1292-1301. doi: 10.1094/PDIS-09-100626

Thinakaran, J., Pierson, E., Kunta, M., Munyaneza, J. E., Rush, C. M., and Henne, D. C. (2015). Silverleaf nightshade (Solanum elaeagnifolium), a reservoir host for 'Candidatus Liberibacter solanacearum', the putative causal agent of zebra chip disease of potato. Plant Dis. 99, 910-915. doi: 10.1094/PDIS-12-14-1254RE

Tusiime, G., Adipala, E., Opio, F., and Bhagsari, A. S. (1997). "Weeds as latent hosts of Ralstonia solanacearum in highland Uganda: implications to development of an integrated control package for bacterial wilt," in Bacterial Wilt Disease: Molecular and Ecological Aspects, eds P. Prior, C. Allen, and J. Elphinstone (Berlin: Springer-Verlag), 413-419. doi: 10.1007/978-3-662-035 92-4_63

Van Elsas, J. D., Kastelein, P., Van Bekkum, P., Van der Wolf, J. M., De Vries, P. M., and Van Overbeek, L. S. (2000). Survival of Ralstonia solanacearum biovar 2, the causative agent of potato brown rot, in field and microcosm soils in temperate climates. Phytopathology 90, 1358-1366. doi: 10.1094/PHYTO.2000.90.12.1358

Wenneker, M., Verdel, M. S. W., Groeneveld, R. M. W., Kempenaar, C., Van Beuningen, A. R., and Janse, J. D. (1999). Ralstonia (Pseudomonas) solanacearum race 3 (biovar 2) in surface water and natural weed hosts: first report on stinging nettle (Urtica dioica). Eur. J. Plant Pathol. 105, 307-315. doi: 10.1023/A:1008795417575

Conflict of Interest: The authors declare that the research was conducted in the absence of any commercial or financial relationships that could be construed as a potential conflict of interest.

Publisher's Note: All claims expressed in this article are solely those of the authors and do not necessarily represent those of their affiliated organizations, or those of the publisher, the editors and the reviewers. Any product that may be evaluated in this article, or claim that may be made by its manufacturer, is not guaranteed or endorsed by the publisher.

Copyright (c) 2021 Sebastià, de Pedro-Jové, Daubech, Kashyap, Coll and Valls. This is an open-access article distributed under the terms of the Creative Commons Attribution License (CC BY). The use, distribution or reproduction in other forums is permitted, provided the original author(s) and the copyright owner(s) are credited and that the original publication in this journal is cited, in accordance with accepted academic practice. No use, distribution or reproduction is permitted which does not comply with these terms. 